\title{
$\mathrm{PH} 9 \mathbf{1}_{\text {panorama }}$
}

\section{Pantalla Viva: una experiencia de recuperación del patrimonio inmaterial con jóvenes}

Durante la segunda quincena del mes de agosto del 2016 se celebró en Galaroza, en pleno corazón de la sierra, una experiencia de recuperación de patrimonio inmaterial de la oralidad a través del cine documental. En el marco de los campos de trabajo para jóvenes ofertados por el Instituto Andaluz de la Juventud se encuadró esta experiencia denominada Pantalla Viva. Durante quince días, veinticinco jóvenes llegados de distintos lugares de la península fueron formados en técnicas de recogida de oralidad, biblioteca humana y producción audiovisual. A partir de ahí, montaron cuatro productoras y fueron a la búsqueda de informantes para la realización de sus microdocumentales.

Manuel Garrido Sevillano | coordinador del campo de trabajo Pantalla Viva

URL de la contribución <www.iaph.es/revistaph/index.php/revistaph/article/view/3903>

Como todo trabajo que tiene su nacimiento en la palabra, en lo oral, también lo tiene en la escucha. Los jóvenes que integraron la experiencia Pantalla Viva: el cine documental como herramienta de recuperación y conservación del patrimonio inmaterial de la oralidad de la sierra de Huelva pudieron comprobaron en primera persona que sin escucha no hay relato, y cómo éste está conformado de varias dimensiones, desde la literalidad a la transferencia, pasando por el significante.

Después de valorar las mil y una posibilidades en cuanto a temas que la sierra ofrece, los 25 participantes decidieron rescatar y contar historias como la relación que los serranos tienen con el agua, las leyendas y mitos referidas a la luna como protagonista, el paso del tiempo, la botánica curativa, los juegos antiguos y los oficios perdidos.

Como es habitual, en el rico debate de temas cercanos, se despierta la necesidad de tomar en consideración ese patrimonio inmaterial que a veces nos pasa desapercibido por cotidiano, y emerge de forma natural la certeza de que el patrimonio no lo compone únicamente una lista de objetos a proteger, sino que las actividades humanas y su relación con los bienes físicos son patrimonio y se unen, en este caso, por la voz y la imagen.
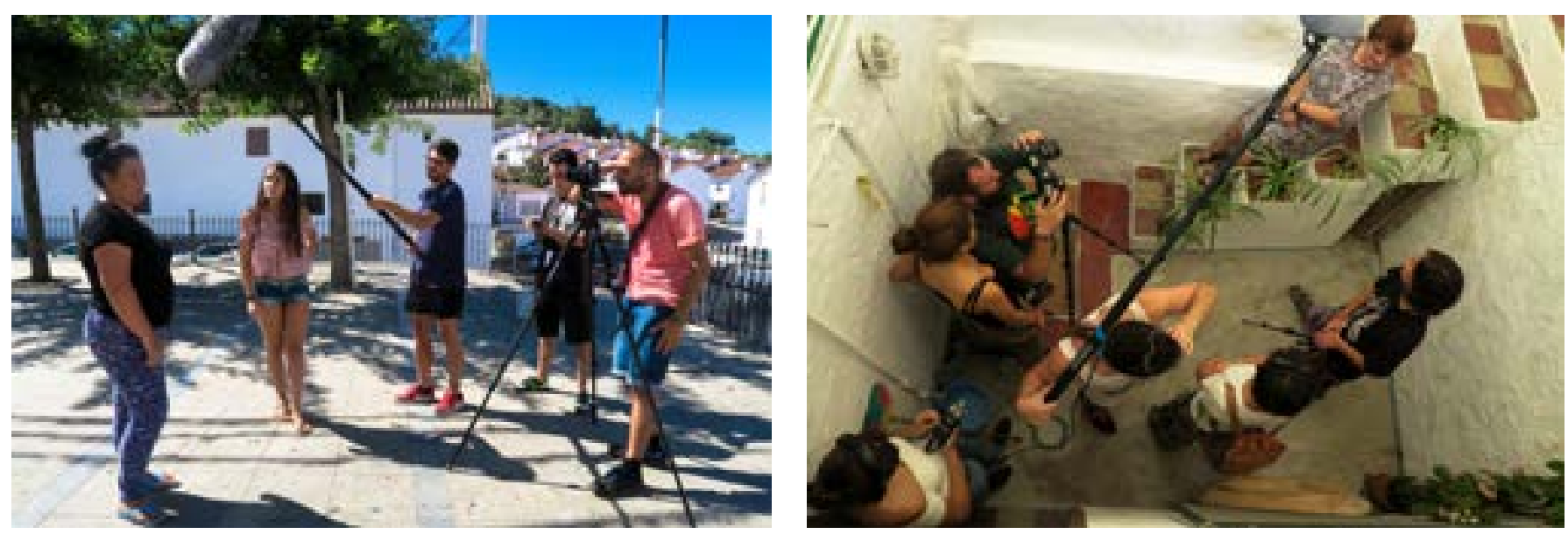
Para poder grabar los microdocumentales, los equipos contaron con la generosidad y la entrega del pueblo de Galaroza, su Ayuntamiento y la comarca. Personas que dieron cuerpo y, sobre todo, voz al trabajo de recuperación planteado con los jóvenes.

Las mañanas estaban dedicadas a las grabaciones y labores de producción, mientras que las tardes fueron compartidas con profesionales de distintos campos como la antropología, el cine documental, con la participación de directores, realizadores y productores que complementaron con su contacto e intercambio lo que por la mañana se iba descubriendo.

En el tiempo que, dentro de cualquier actividad de estas características, está reservado para el ocio, Pantalla Viva se abrió a la población: un marcado carácter popular y patrimonial; conciertos de música tradicional; sesiones nocturnas de cuentos en mitad de la calle; cine de verano; y noches de danzas populares, conectaron a participantes y pueblo.

Durante el tiempo de duración del campo, los jóvenes crearon, como no podía ser de otra manera una relación fecunda y afectiva a través de la palabra, que luego se transformó en imagen. Podríamos decir que durante este periodo se creó una auténtica "comunidad patrimonial" donde por un lado estaba la población con ideas claras del patrimonio que conservan y por otro los jóve- nes deseosos de que les fuera transmitido. Una prueba en definitiva de la necesidad, la voluntad y la posibilidad de participación activa.

Como cierre del campo se exhibió una muestra del trabajo realizado, bajo el nombre de El Cine que Era, en la antigua era del pueblo, a modo de velada popular de cine de verano, al que llegaron a asistir más de trescientas personas. La muestra fue el colofón a la gran participación y dejó patente, de forma indiscutible, que las zonas rurales son bastante más que espacios de producción de alimentos y materias primas, son también lugares llenos de conocimiento y patrimonio a recuperar, habitados por gentes que conservan una poética inmaterial.

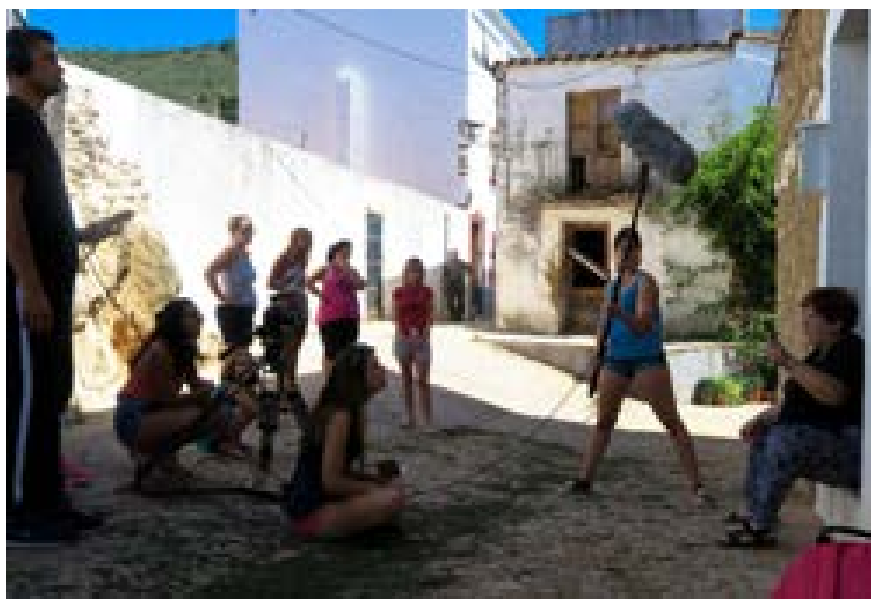

Diferentes momentos del proceso de grabación | fotos Javier Esquivias Segura

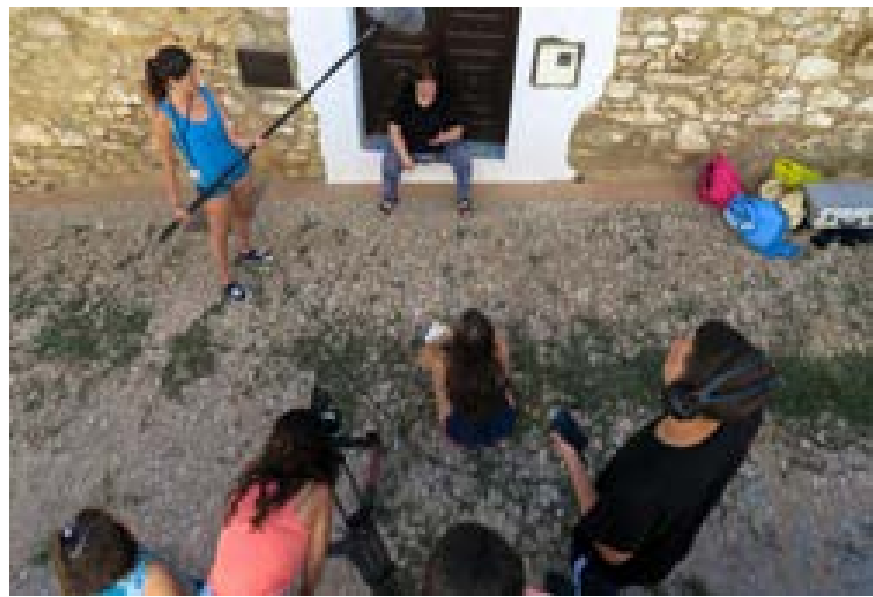

